\title{
Tribunal de Contratación Pública: bases INSTITUCIONALES, ORGANIZACIÓN, COMPETENCIA Y PROCEDIMIENTO*
}

[Court of Public Procurement.

Institutional bases, organization, jurisdiction and procedure]

\author{
Alejandro Vergara Blanco**
}

\begin{abstract}
RESUMEN
El autor analiza las bases institucionales, organización, competencia y procedimiento ante el Tribunal de Contratación Pública creado en 2003 para conocer la acción de impugnación contra cualquier acto u omisión ilegales $\mathrm{o}$ arbitrarios que tengan lugar durante el
\end{abstract}

\begin{abstract}
The author analyzes the institutional bases, organization, jurisdiction and procedure before the Court of Public Procurement established in 2003 to meet the challenge action against any act or illegal or arbitrary omission occurring during the government contracting pro-
\end{abstract}

RECiBido el 26 de marzo y ACEPTADO el 31 de mayo de 2016

* Abreviaturas especiales: $\mathrm{CPC}=$ Código de Procedimiento Civil; $\mathrm{CPR}=$ Constitución Política de la República; COT = Código Orgánico de Tribunales; LBCA = Ley No19.886 de 2003 que establece Bases sobre contratos administrativos de suministro y prestación de servicios; LBPA = Ley No 19.880 de 2003 que establece Bases de los procedimientos administrativos que rigen los actos de los órganos de la Administración del Estado; LOCBGAE = Ley N 18.575 de 1986, Orgánica Constitucional de Bases Generales de la Administración del Estado. Diario Oficial, 5 diciembre 1986; LOCM = Ley 18.695, Orgánica Constitucional de Municipalidades de 1986; y, TCP = Tribunal de Contratación Pública.

** Profesor Titular de Derecho Administrativo de la Facultad de Derecho de la Pontificia Universidad Católica de Chile. Correo postal: Av. Libertador Bernardo O’Higgins 340, Santiago, Chile. Correo electrónico: alvergar@uc.cl 
procedimiento de contratación administrativa ante órganos de la Administración del Estado, ocurridos entre la aprobación de las bases de la respectiva licitación y su adjudicación.

Palabras Clave

Contratación administrativa - Tribunal de contratación pública - Derecho Administrativo - procedimiento de compras. cedures, occurred between the approval of the terms of the respective tender and adjudication.

\section{KEYWORDS}

Public Procurement - Court of Public Procurement - Administrative Law - procurement procedure.

El Tribunal de Contratación Pública (TCP), creado en 2003 (pero que entró en funcionamiento en 2005) es el juez especializado de la contratación administrativa y fue el iniciador de la actual tendencia de justicia administrativa fraccionada e híper especializada ${ }^{1}$; otros tribunales administrativos especializados han continuado esta tendencia ${ }^{2}$. La regulación del TCP está contenida en los artículos 22 a 27 LBCA.

\section{ORIGEN Y REGULACIÓN BÁSICA DEL TCP}

El Proyecto de Ley de la que sería la LBCA fue fruto de un Plan Estratégico propulsado por un Comité Interministerial de Modernización

${ }^{1}$ Véase una descripción más detallada sobre ese fenómeno de creación de tribunales híper especializados en: Vergara Blanco, Alejandro, Esquema del contencioso administrativo: su tendencia hacia un modelo mixto y situación actual del recurso de protección, ahora, en Arancibia M., Jaime - MarTínez E., José - Romero S., Alejandro (coordinadores), Litigación Pública, colección Estudios de Derecho Público, Primer Seminario de Litigación Pública (Santiago, Universidad de los Andes, Abeledo PerrotThomson Reuters, 2011), pp. 37-63; Vergara BlanCO, Alejandro, El nuevo paradigma de jurisdicción administrativa pluriforme e hiperespecializada: crónica de una espera, como la de Godot, en Anuario de Derecho Público (Santiago, Universidad Diego Portales, 2014), pp. 269-292 y Vergara Blanco, Alejandro, La tendance actuelle du droit chilien pour une jurisdiction administrative hyper-spécialisée, en Mélanges en l'honneur de Pierre Bon (París, Éditions Dalloz, 2014), pp. 126-140.

${ }^{2}$ Fueron creados con posterioridad: i) el Panel de Expertos en Electricidad (Ley $\mathrm{N}^{\circ} 19.940$ de 2004, que modificó la Ley general de servicio eléctricos); ii) el Consejo para la Transparencia (Ley $\mathrm{N}^{\circ} 20.285$ de 2008); iii) los Tribunales Tributarios y Aduaneros (Ley $\mathrm{N}^{\circ} 20.322$ de 2009); y iv) los Tribunales Ambientales (Ley $\mathrm{N}^{\circ}$ 20.600 de 2012). 
de la Gestión Pública que en 1998 aprobó un Programa de Reforma al Sistema de Compras y Contrataciones; además, los acuerdos en materia de libre comercio con Estados Unidos y con la Unión Europea en 2003 constituyeron también un impulso para su creación ${ }^{3}$.

\section{En el origen, sólo se consideraba una acción de reclamación}

En un inicio el proyecto de Ley preveía únicamente un recurso especial de "reclamación" ante la propia Administración (el cual se entendía de manera independiente al resto de las herramientas de impugnación de los actos de la Administración establecidos en las leyes vigentes (reposición y jerárquico ${ }^{5}$. En 2001 se dio un cambio radical en el Proyecto en materia de impugnaciones, proponiéndose la creación de un Tribunal especializado en materia de compras, denominado inicialmente Tribunal de Compras y Contratación Pública.

\section{Discusión parlamentaria sobre el TCP}

a) Reticencia inicial a aceptar la creación del TCP.- Se intentó inicialmente bloquear la creación del TCP para dar paso al antiguo anhelo de crear los tribunales del contencioso administrativo. En el primer Informe de la Comisión de Constitución de 18 de noviembre de 2002 (Comisión de Hacienda, segundo trámite constitucional), se afirma que la creación de dicho Tribunal "da cuenta de una suerte de desorden en la formulación de políticas y propuestas legislativas por parte del Ejecutivo". Lo anterior pues existía en el Ministerio de Justicia una comisión encargada de estudiar la creación de los tribunales contenciosos administrativos, para dar cumplimiento en mejor forma al inciso segundo del artículo 38 de la Constitución Política de la República (CPR), y para algunos resultaba inexplicable la creación paralela de este nuevo tribunal especial ${ }^{6}$.

${ }^{3}$ Véase Biblioteca del Congreso Nacional de Chile (2003): Historia de la Ley No19.886, de Bases sobre Contratos Administrativos de Suministro y Prestación de Servicios, pp. 10,11 y 142 .

${ }^{4}$ Señalaba el art. 44, Cap. VII del Proyecto: "Cualquier persona que participe en los procedimientos de contratación, podrá reclamar en contra de las acciones u omisiones de la Administración que estime arbitrarias e ilegales y que se ejecuten en el desarrollo de tales procedimientos, dentro del plazo de 10 días contados desde la fecha de las acciones o desde el requerimiento, en el caso de las omisiones, ante la Dirección de Compras Públicas".

5 Según disponía desde 1986 el art.9 LOCBGAE, única norma administrativa que de modo genérico regulaba a la época tales recursos al interior de la Administración.

${ }^{6}$ Biblioteca del Congreso, cit. (n. 3), p. 195. Lo citado fue sostenido por el Senador y notable autor de Derecho Administrativo, Enrique Silva Cimma, quien 
b) Respuesta ante la falta de consenso para crear el TCP.En el mismo Informe se consigna que el Ministro de Justicia señaló "que el proyecto intenta cautelar que lo que ocurra en materia de administración de justicia, en el país, sea coherente con otras decisiones políticas y legislativas que se han tomado; $y$, en ese sentido, es adecuada la creación de un tribunal especial que permita que la resolución de los conflictos que se generen en esta materia, sea más rápida de lo que ocurre en la actualidad". Los criterios que inspiraban a esa Secretaría de Estado habrían sido: primero, "que no se conformen tribunales especiales sobre la base de jueces integrantes de los tribunales ordinarios, atendido el retraso en el despacho de causas que presenta la jurisdicción ordinaria” y, segundo, "que se profesionalice el apoyo administrativo y, consiguientemente, se puedan transformar los actuales secretarios de juzgados en jueces, lo que permitiría duplicar la capacidad jurisdiccional existente" 7 .

c) Consenso en avanzar sin esperar la creación de los tribunales del contencioso administrativo.- Señala, en fin, tal Informe que: "Al término del debate, no obstante las prevenciones expresadas, hubo consenso en la Comisión en que esta materia debe enfrentarse con prontitud, y, en ese sentido, es preferible que prosiga la tramitación de la iniciativa en informe a esperar la creación de los tribunales contenciosos administrativos (...)" .

d) Informes de la Corte Suprema sobre la creación del TCP.- La Corte Suprema emitió dos informes relativos a dos versiones del Proyecto: i) el primer Informe, de 24 de julio de 2001, comunica de modo

además (según se consigna en el Informe) señala que: “Con este procedimiento se está eludiendo el problema de fondo, que se refiere precisamente a la creación de los tribunales contenciosos administrativos". Biblioteca del Congreso, cit. (n. 3), p. 196.

${ }^{7}$ El Ministerio de Justicia agrega los siguientes antecedentes: i) que "el proyecto de ley regula un procedimiento de contratación pública que recoge las normas más avanzadas del derecho comparado"; ii) que "se contemplan reglas generales de procedimiento para todos los servicios públicos, lo que en la actualidad no existe, junto con una serie de disposiciones de transparencia para la realización de los procesos de contratación"; iii) que "debido a la creación de este nuevo sistema, es preciso que exista una instancia judicial específica, concordante con las decisiones de carácter internacional adoptadas por el país, ya que en la casi totalidad de los acuerdos comerciales internacionales se establecen tribunales especiales, independientes de la administración ordinaria de justicia, para resolver las disputas relacionadas con la contratación pública", y iv) en fin, que "ello, al mismo tiempo, permitirá centralizar en un solo organismo las variadas reclamaciones que se presenten, y que hoy se disgregan en diferentes servicios públicos, que no siempre cuentan con la capacidad técnica y humana para resolverlas." En: Biblioteca del Congreso, cit. (n. 3), p. 196-197.

${ }^{8}$ Biblioteca del Congreso, cit. (n. 3), p. 197. 
implícito su parecer favorable, sin perjuicio de algunas observaciones ${ }^{9}$; ii) en un segundo Oficio remitido por la Corte Suprema a la Cámara de Diputados el 17 de junio de 2002 si bien la Corte informó favorablemente el proyecto de ley por mayoría, contiene diversas observaciones ${ }^{10}$. Varias de ellas fueron incorporadas al Proyecto.

e) Control de constitucionalidad.- El Tribunal Constitucional se pronunció sobre el Proyecto de Ley en especial por la creación de un Tribunal (en virtud de los arts. 77 y $93 \mathrm{~N}^{\circ} 1 \mathrm{CPR}$ ) en sentencia de 18 junio 2003 (Rol No 378-03), declarando la constitucionalidad del articulado respectivo.

\section{Resultado legislativo: una regulación escueta}

En definitiva el TCP fue creado y regulado en los artículos 22 a 27 de la LBCA (Capítulo V: Del Tribunal de contratación pública).

a) Regulación legal.- Su escueta regulación legal ha sido criticada por la doctrina en general, considerándola "parca» 0 "breve» ${ }^{11}$. La LBCA regula las siguientes materias relacionadas con este tribunal: i) creación, composición, aspectos orgánicos y financieros (arts. 22 y 23 LBCA); ii) competencia, acción de impugnación y procedimiento (arts. 24, 25 y26 LBCA); y, iii) potestades del TCP en la dictación de la sentencia y recursos que proceden (arts. 26 y 27 LBCA).

A lo anterior cabe agregar: i) en relación a los contratos de obra pública, el art.3e) in fine LBCA; ii) en relación a la contratación que realicen las

9 Sus observaciones fueron: i) que el personal de secretaría lo designe el propio tribunal; ii) postula la competencia amplia del tribunal. En efecto, a su juicio la competencia del futuro TCP "deberá comprender las reclamaciones que interponga cualquier persona que sea lesionada en sus derechos, cometidos por los organismos públicos regidos por esta ley [citando al efecto el art.38 de la Constitución], en las materias que le sean propias" y que "la competencia restringida que se le atribuye no justifica su creación”, y iii) como el Proyecto contemplaba la integración de un ministro de la Corte de Apelaciones de Santiago, la Corte Suprema señala en su informe que "se podría aceptar que formara parte del tribunal un juez en lo civil [pero no un ministro de corte]”. En: Biblioteca del Congreso, cit. (n. 3), p. 86.

${ }^{10}$ Entre las cuales cabe destacar: i) reitera la inconveniencia de incorporar ministros de la Corte de Apelaciones de Santiago al TCP; ii) califica expresamente al TCP como un "tribunal especial" de aquellos que forman parte del Poder Judicial (citando al efecto el art. 5 del Código Orgánico de Tribunales); iii) realiza varias observaciones sobre el procedimiento. En: Biblioteca del Congreso, cit. (n. 3), p. 193.

${ }^{11}$ También se ha referido a esta incompleta regulación el actual Presidente de este Tribunal. Vid. en ARÉVALO ADASME, Álvaro, Rol del Juez en el proceso administrativo licitatorio. Discurso en el "Seminario de Contratación Administrativa y Compras Públicas”, celebrado el 28 de mayo de 2014 en la Facultad de Derecho de la Pontificia Universidad Católica de Chile, p. 6. 
municipalidades y al otorgamiento de concesiones para la prestación de servicios por tales municipalidades, el art. 66 LOCM, según modificación de la Ley $N^{\circ} 20.355$ de 2009; y, iii) en relación al procedimiento, se aplica supletoriamente el CPC según el art. 27 LBCA.

b) Auto Acordado de la Corte Suprema sobre el funcionamiento del Tribunal de Contratación Pública.- Según el art.25 inciso final LBCA: "Un auto acordado, dictado por la Corte Suprema, regulará las materias relativas a su funcionamiento administrativo interno, velando por la eficaz expedición de los asuntos que conozca el Tribunal". Así, para el funcionamiento y la organización del TCP la Corte Suprema dictó un Auto Acordado el 30 de diciembre de 2003 (posteriormente refundido, tras varias modificaciones, en virtud del Auto Acordado de 22 de marzo de 2011) ${ }^{12}$, el que prevé con mayor detalle su funcionamiento así como una mayor concreción de los sistemas de nombramiento de los jueces y del Ministro de Fe.

\section{Bases institucionales del Tribunal de Contratación PÚBLICA}

\section{Naturaleza jurisdiccional}

El TCP es un "tribunal establecido por la ley", en los términos del art. 76 inc. $1^{\circ} \mathrm{CPR}^{13}$. Es un tribunal especial y de Derecho.

a) Carácter especial del TCP.- EL TCP fue creado como especializado, por su conformación y designio. Fue creado al mismo tiempo en que se regulaba por vez primera la materia de contratación administrativa (cuya única norma anterior era el art. $9^{\circ}$ LOCBGAE), y bajo la idea de que un buen sistema de resolución de conflictos debe ser especializado, es decir, la necesidad de contar con un tribunal altamente capacitado en la materia en conflicto a fin de abarcar todas las complejidades de dichas materias, cuyos integrantes sean profesionales con experiencia comprobada en las mismas; y que de ese modo además puedan garantizarse otros fines: i) su

${ }_{12}$ Véase: Auto Acordado sobre funcionamiento del Tribunal de Contratación Pública texto refundido, 11 de marzo de 2011, Acta No 16-2011, en: http://autoacordados. pjud.cl/\#parrafo989. Este Auto Acordado especifica que las sesiones del órgano jurisdiccional se llevan a cabo los martes y jueves de cada semana, cabiendo excepcionalmente sesionar un día más, en caso de sobreacumulación de trabajo (pero este último aspecto ha sido modificado por la Ley $\mathrm{N}^{\circ} 20.883$, de 2015, que modificó el art. 22 LBCA, según señalo más delante)

${ }^{13} \mathrm{El}$ art. 76 inc. $1^{\circ} \mathrm{CPR}$ dispone: "La facultad de conocer de las causas civiles y criminales, de resolverlas y de hacer ejecutar lo juzgado, pertenece exclusivamente a los tribunales establecidos por la ley”. 
independencia y autonomía, tanto de la Administración del Estado como de los particulares, en la toma de decisiones, y ii) enfrentar adecuadamente la especialidad, la rapidez, la tecnicidad y la complejidad que presenta la resolución de conflictos en esta área específica.

Si bien ese objetivo de especialización, se cumple en la regulación del TCP (véase más adelante lo que digo sobre la designación de sus integrantes), no quedó explicitado a los efectos del art. 76 inc. $3^{\circ} \mathrm{CPR}$ y 5 COT si se considera que forma parte del Poder Judicial, en cuyo caso opera la clasificación de los tribunales en ordinarios y especiales. Entonces, el TCP es un tribunal "especial" por dos razones: primero, por su origen y regulación también especial de la LBCA y, segundo, al tratarse de un tribunal que forma parte del poder Judicial, y dado que estos se clasifican en ordinarios y especiales, pareciera que esta última es su condición. Con todo, la ley no es explícita y esto es el fruto de una interpretación razonada de sus vacíos al respecto.

b) Tribunal de derecho, inexcusabilidad y principios.- El art. 76 inc. $2^{\circ} \mathrm{CPR}^{14}$ consagra para todo tribunal, como es el caso del TCP, la regla del non liquet, esto es, la inexcusabilidad, en cuya virtud los tribunales no pueden excusarse de emitir su decisión; siempre deben fallar, ya sea en conformidad a reglas o a principios. Los arts. 22 inc. $8^{\circ}$ ("conforme a derecho") y 26 inc. $1^{\circ}$ ("imperio del derecho") LBCA son coherentes con este designio constitucional incorporando con esas paradigmáticas expresiones la necesidad de ejercer la jurisdicción con un canon de integridad o completitud de fuentes, aplicando tanto reglas o leyes (cuando las hay) o principios (en caso de lagunas legales). La propia ley que lo crea, como se ve, insta al TCP a evitar una visión meramente legalista y a abrirse más ampliamente a los principios, los que siempre están más allá de la ley, como recurso para colmar lagunas legales.

\section{Efecto y cumplimiento de las decisiones del TCP}

a) Cosa juzgada de las decisiones del TCP.- Dado que el TCP es un órgano cuya competencia es de naturaleza jurisdiccional y en caso de que las partes respectivas no recurran de sus decisiones, opera en éstas el efecto de la cosa juzgada; su naturaleza jurisdiccional y la cosa juzgada derivada de sus decisiones no ha sido puesta en duda, y ha sido reafirmada en doctrina y por la propia Corte Suprema en una importante y expresiva sentencia ${ }^{15}$.

${ }^{14} \mathrm{El}$ art. 76 inc. $2^{\circ} \mathrm{CPR}$ dispone: "Reclamada su intervención en forma legal y en negocios de su competencia, no podrán excusarse de ejercer su autoridad, ni aun por falta de ley que resuelva la contienda o asunto sometidos a su decisión."

15 En doctrina, Bermúdez Soto, Jorge, 2011, Derecho Administrativo General, 
b) Potestad de imperio del TCP.- Para saber si el TCP tiene la potestad de imperio cabe verificar previamente si se lo considera o no formar parte del Poder Judicial, de acuerdo al art. 76 inc. $3^{\circ} \mathrm{CPR}^{16}$ Cabe recordar que la propia Corte Suprema, durante la tramitación de la LBCA, en su segundo informe de 17 de junio de 2002 (al que me refiero más arriba), consideró expresamente al TCP como parte del Poder Judicial, calificándolo además como "especial", de aquellos enumerados en el art. 5 COT. No obstante, al crear la Ley el TCP no se consignó tal calificación en el texto de la LBCA ni se agregó el TCP en el art. 5 COT. Pero el art. 22 inc. penúltimo LBCA señala que el TCP está sujeto a la superintendencia directiva, correccional y económica de la Corte Suprema, lo que en estricto rigor no era necesario dados los términos explícitos del art.79 CPR que sujeta a tal superintendencia a "todos los tribunales de la Nación". La LBCA no establece un mecanismo especial para el cumplimiento de las sentencias del TCP (para el ejercicio de su potestad de imperio), por lo que al aplicar la regla del art. 2 CPC el cumplimiento de las sentencias del TCP se regirá por la tramitación común del procedimiento ordinario. Persiste en todo caso la duda interpretativa de si ese cumplimiento lo puede realizar directamente el propio TCP o habrá que recurrir a un tribunal ordinario; la respuesta dependerá de si se considera o no al TCP como formando parte del Poder Judicial. La respuesta es positiva pues el TCP tiene potestad de imperio por los fundamentos señalados.

pp. 235, lo califica concretamente de "órgano jurisdiccional especial”. En jurisprudencia véase Montenegro con Municipalidad de Santiago y Parquímetros y Controles (2012), como la Corte Suprema en una notable sentencia (redactor: Ministro Sergio Muñoz), señala que: “(...) el Tribunal de Contratación Pública, en lo que respecta a su competencia, es un tribunal contencioso administrativo de licitaciones contractuales (...); su competencia comprende la facultad de adoptar las medidas necesarias para corregir las incorrecciones juridicas producidas durante el proceso de compra y que dicho órgano jurisdiccional observe en el curso del procedimiento (...); el Tribunal de Contratación Pública se encuentra dotado de competencia amplia en torno a los procedimientos que se impugnan ante sus estrados (...)". Todo ello para reafirmar la plena competencia de dicho TCP para dejar sin efecto todo un procedimiento licitatorio, en caso de que sea necesario para dar eficacia a las reglas y principios de la LBCA, con lo cual no hace "sino actuar dentro de los límites de su competencia".

${ }^{16} \mathrm{El}$ art. 76 inc. $3^{\circ} \mathrm{CPR}$ dispone: "Para hacer ejecutar sus resoluciones, y practicar o hacer practicar los actos de instrucción que determine la ley, los tribunales ordinarios de justicia y los especiales que integran el Poder Judicial, podrán impartir órdenes directas a la fuerza pública o ejercer los medios de acción conducentes de que dispusieren. Los demás tribunales lo harán en la forma que la ley determine.” 


\section{ORganización Del TRIBUnAL}

\section{Estructura del TCP: tribunal colegiado}

El Tribunal tiene su asiento en Santiago y está conformado por tres "integrantes" (como los llama la propia ley). Se agregan sus respectivos suplentes, los que ejercen el cargo a falta de aquéllos (art. 22 incs. $1^{\circ}$ y $2^{\circ}$ LBCA). Por lo tanto, los jueces de este tribunal colegiado son sus tres integrantes (titulares) más sus tres suplentes. Además, un abogado a contrata ejerce la función de ministro de fe del Tribunal (art. 23 inc. $1^{\circ}$ LBCA). A ello se agrega el personal administrativo.

a) Nombramiento de sus jueces integrantes.- Los tres jueces integrantes, previa propuesta en terna hecha por la Corte Suprema, son designados por el Presidente de la República. Posteriormente, éstos elegirán a uno de sus miembros para que ejerza como presidente por un periodo de dos años, pudiendo ser reelegido. La duración de los cargos es por cinco años, si bien cabe nuevamente su designación ${ }^{17}$.

b) Requisitos copulativos de los candidatos a jueces integrantes.- El art. 22 inc. $3^{\circ}$ LBCA es explícito en la exigencia de "experiencia" de sus integrantes (de donde se origina la especialidad del propio TCP); pues de acuerdo a la literalidad de la ley los siguientes son los cuatro requisitos copulativos ${ }^{18}$ que deben cumplir los candidatos a formar parte del Tribunal, en base a los cuales se deben confeccionar entonces las ternas respectivas por la Corte Suprema: $1^{\circ}$ ) ser abogado chileno; $2^{\circ}$ ) haberse destacado en la actividad profesional o universitaria; $3^{\circ}$ ) acreditar experiencia en la materia; $y 4^{\circ}$ ) tener no menos de diez años de

${ }^{17}$ Lara Arroyo, José Luis y García-Huidobro Herrera, Luis Eugenio, Aspectos críticos de la solución de controversias en la Contratación Administrativa bajo la Ley No19.886: El caso del Tribunal de Contratación Pública, en Lara Arroyo, José Luis y Bocksang Hola, Gabriel (coordinadores), Procedimiento Administrativo y Contratación Pública. Estudios a diez años de la entrada en vigencia de las leyes 19.880 y 19.886 (Santiago, LegalPublishing - Thomson Reuters, 2013), p. 422-423, han propuesto que sea el Consejo de Alta Dirección Pública el ente encargado del nombramiento de los integrantes del TCP, en vez de la Corte Suprema. Pero no es necesario tal cambio, en la medida que la Corte Suprema sea leal, en la elaboración de las ternas, con el encargo legal de la especialidad de los nominados, eligiendo sólo expertos en la materia.

${ }_{18}$ Obsérvese la conjunción copulativa " $y$ ” en medio de la enumeración de los cuatro requisitos; y sólo respecto de los requisitos números segundo y cuarto se utiliza la conjunción disyuntiva "o" en el art. 22 inc. $3^{\circ}$ LBCA. Su texto expreso es el siguiente: "En la señalada lista sólo podrán figurar abogados que sean chilenos; se hayan destacado en la actividad profesional o universitaria; acrediten experiencia en la materia, y tengan no menos de diez años de ejercicio profesional o hayan pertenecido al Escalafón Primario del Poder Judicial, siempre y cuando hubieran figurado durante los últimos cinco años en Lista Sobresaliente." 
ejercicio profesional o haber pertenecido al Escalafón Primario del Poder Judicial, siempre y cuando hubiera figurado durante los últimos cinco años en Lista sobresaliente. La Corte Suprema debiese, además, realizar un proceso de selección abierto y competitivo, con la exigencia explícita que los candidatos acrediten los cuatro requisitos copulativos que exige la ley. La especialidad (esto es, la "experiencia en la materia" según la ley) es una exigencia indudable e ineludible en la ternas respectivas; de ahí la necesidad de que los integrantes elegidos no sólo sean abogados o docentes universitarios con dedicación al Derecho en general o a otras disciplinas, sino que deberán contar con experiencia previa y demostrable en materia de licitaciones públicas y contratación administrativa. De otro modo se produce un verdadero fraude a la ley y un rompimiento de un designio legislativo: la especialidad del TCP. En esta materia se requieren jueces con experiencia y conocimientos específicos ${ }^{19}$.

\section{Infraestructura y recursos materiales y humanos}

El TCP no tiene actualmente sede propia y la infraestructura, apoyo técnico y los recursos humanos y materiales necesarios para su funcionamiento los provee la Dirección de Compras y de Contratación Pública (en adelante, indistintamente, Dirección de Compras). Es la autoridad administrativa, curiosamente, la que según la ley ha de proveer infraestructura y recursos humanos y materiales para el funcionamiento del TCP (art. 23 inc. $\left.3^{\circ} \mathrm{LBCA}\right)^{20}$. Por su parte el auto acordado de la Corte Suprema señala que: i) el TCP "funcionará en la ciudad de Santiago y tendrá su sede y domicilio en el recinto que habilitará y destinará exclusivamente a este objeto la Dirección de Compras y Contratación Pública”; y ii) en cuanto al recinto, que "deberá poseer las dependencias y condiciones necesarias para permitir el expedito y cómodo funcionamiento del Tribunal, de su Secretaría y Archivo y asegurar su independencia institucional".

La falta de infraestructura propia del TCP es un riesgo para su independencia, pues no parece adecuado para la autonomía del TCP que dependa en los aspectos presupuestarios, de recursos humanos y logísticos de la Dirección de Compras, ante la posibilidad de surgir una impugnación de un proceso licitatorio promovido por la Dirección de Compras, lo cual no

19 Como observa Costa, la virtud de crear dichos órganos responde a la necesidad de abordar temas de alta complejidad técnica, y para ello se requiere de personas altamente capacitadas para resolverlos. Costa Cordella, Ezio, Los Tribunales Administrativos especiales en Chile, en Revista de Derecho (Valdivia) N²1 (2014) p. 156.

${ }^{20} \mathrm{El}$ art. 23 inc. $3^{\circ}$ LBCA señala: "La Dirección de Compras y Contratación Pública deberá proveer la infraestructura, el apoyo técnico y los recursos humanos y materiales necesarios para el adecuado funcionamiento del Tribunal". 
es nada extraño, sino más bien corriente. Para la independencia de la tarea jurisdiccional asignada al TCP se hace necesario contar con las condiciones que aseguren su autonomía funcional y económica, libre de toda atadura de cualquier tipo que pueda interferir en tal cometido. En especial, un local o sede que funcione separadamente de la Administración. Incluso podría funcionar al interior de alguna sede destinada al Poder Judicial, dada su pertenencia a ese poder del Estado.

En lo referente al presupuesto pareciera necesaria la dotación de una partida presupuestaria totalmente independiente para el $\mathrm{TCP}^{21}$, desvinculada de la Dirección de Compras, la cual fuese autogestionada; además, unos recursos humanos, técnicos y logísticos -incluyendo la sede donde desarrolle su actividad-independientes de la DCCP; todo ello dirigido a garantizar su autonomía e imparcialidad ${ }^{22}$. Como solución para asegurar esta independencia, se ha sostenido ${ }^{23}$ que podría subordinarse al TCP exclusivamente al Ministerio de Hacienda o Economía, lo que de hecho es algo que ya acontece con otros tribunales especializados como en el caso del Tribunal de Defensa de la Libre Competencia o el Tribunal de Propiedad Industrial; pero dicha autonomía pudiese estar también sujeta a posibles tensiones, pues al depender este tribunal de cualquier organismo de la Administración del Estado siempre supondrá un potencial riesgo para su independencia jurisdiccional.

${ }^{21}$ Señala Olmos Carrasco, Felipe, Aspectos orgánicos y competencia del Tribunal de Contratación Pública, en Lara Arroyo, José Luis y Bocksang Hola, Gabriel (coordinadores) Procedimiento Administrativo y Contratación Pública. Estudios a diez años de la entrada en vigencia de las leyes 19.880 y 19.886 (Santiago, LegalPublishing - Thomson Reuters, 2013), p. 457, que, si bien la dependencia presupuestaria ha disminuido en los últimos años, al haber conseguido "una glosa presupuestaria independiente dentro del presupuesto de la Dirección”, critica más abajo que "es inadecuado que el legislador haya entregado [a la] Dirección de Compras y Contratación Pública la función de proveer materialmente al Tribunal, si se considera que la Dirección como organismo público integrante de la Administración del Estado es justiciable ante el Tribunal de Contratación Pública”.

${ }^{22}$ Ello es algo de lo que se ha hecho eco en algunos trabajos: LARA y otro, cit. (n. 17), p. 415; Escanilla Abarza, Eduardo S., El Tribunal de Contratación Pública en Chile. Un análisis crítico propositivo, en Revista de Derecho Público Iberoamericano (2013) p. 123; VÁsquez Santander, Yuri Antonio y Koch Chacón, Maximiliano Alfredo, Institucionalidad, Procedimiento y Jurisprudencia del Tribunal de Contratación Pública. Análisis Jurisprudencial desde su establecimiento hasta la actualidad (Memoria para optar al grado de Licenciado en Ciencias Jurídicas y Sociales, Universidad de Chile, 2014), p. 42.

${ }^{23}$ LARA y otro, cit. (n. 17), p. 418. 


\section{Funcionamiento del TCP.}

El funcionamiento del TCP debe estar adecuado al régimen jurídico aplicable a su procedimiento y labores propias de un tribunal (recibir las demandas y juzgar).

a) Días y horas de funcionamiento.- Señala el Auto Acordado de la CS que "El Tribunal tendrá el mismo horario semanal y diario de funcionamiento que la Dirección [de Compras y Contratación Pública], del cual se destinarán cinco horas diarias a la atención de público”. De ahí que el TCP funciona durante el horario propio de un órgano administrativo (de lunes a viernes) y no en el horario propio de los tribunales (de lunes a sábado), a pesar que el TCP está regido por los horarios que impone el CPC. En efecto, al aplicarse a sus procedimientos el CPC (ex art. 27 LBCA) el horario de funcionamiento del TCP ha de ser el mismo de un tribunal del Poder Judicial, y debiera funcionar de lunes a sábado, excepto domingos y festivos, asegurándose así a los justiciables la atención y recepción de sus demandas en los días hábiles que establece la ley. Por ejemplo, si el término del plazo para presentar una reclamación recayese en día sábado (día hábil según tal código, debiendo funcionar el TCP por lo tanto), el funcionamiento del Tribunal en las dependencias de un órgano administrativo (que no funciona los sábados, de acuerdo a la LBPA) es un desajuste e impide el ejercicio de la garantía de acceso a la jurisdicción. Este es entonces un aspecto desajustado del actual funcionamiento del TCP.

b) Audiencias del TCP. Al respecto cabe distinguir dos etapas.-i) Hasta diciembre de 2015: de acuerdo con el art. 7 del Auto Acordado, las audiencias del TCP se celebraban los días martes y jueves de cada semana, y, excepcionalmente, en atención al volumen y necesidades de trabajo, se pudo funcionar con otra audiencia semanal, por acuerdo del TCP. Cabe considerar derogada esa disposición; ii) en la actualidad: la legislación ha venido en auxilio de un mejor funcionamiento del TCP, y fruto de recientes modificaciones al art. $22 \mathrm{LBCA}^{24}$ : se aumenta el número de sesiones mensuales del TCP, de 12 a 21, con un máximo de una sesión diaria (nuevo texto del inciso $6^{\circ}$ ); y, se optimiza la función de los jueces suplentes (añadiendo un inciso $7^{\circ}$ nuevo).

\section{COMPETENCIA Y ACCIÓN DE IMPUGNACIÓN}

El TCP tiene una acotada competencia dentro de cuyo ámbito surgen

${ }^{24}$ Modificada por la Ley No 20.883 de 2015, que otorga reajuste de remuneraciones a los trabajadores del sector públicos, concede aguinaldos que señala y concede otros beneficios que señala (Diario Oficial, 2 de diciembre de 2015), a través de su art. 41 modifica el art. $22 \mathrm{LBCA}$, en su inciso $6^{\circ}$ y agrega un nuevo inciso $7^{\circ}$. 
las causales para la interposición de la acción de impugnación, lo que reviso de acuerdo a su regulación legal en conjunto con diversos pronunciamientos jurisprudenciales.

\section{Una competencia acotada a la fase de licitación}

a) Regla general de competencia del TCP. Existe una regla general de competencia contenida en art. 24 incs. $1^{\circ}$ y $2^{\circ} \mathrm{LBCA}^{25}$, según la cual el TCP conoce: i) los conflictos derivados de todos los actos y omisiones ilegales o arbitrarias acaecidos en los procedimientos administrativos de contratación con los organismos públicos regidos por la LBCA (esto es, los organismos señalados en el art. $1^{\circ}$ inc. $2^{\circ} \mathrm{LBCA}$ ), y ii) que se hayan suscitado "entre la aprobación de las bases de la respectiva licitación y su adjudicación, ambos inclusive".

Curiosa es entonces la denominación que recibió el TCP en razón a su acotada competencia, la cual no comprende todos los conflictos a que dé lugar la contratación administrativa en todas sus fases, desde su gestación hasta su término y ejecución, sino que la competencia del TCP únicamente comprende la primera etapa de tal contratación: la licitación; según la ley: "entre la aprobación de las bases de la respectiva licitación y su adjudicación, ambos inclusive". Dejando de ese modo al margen las siguientes etapas de la contratación, desde el momento posterior a la adjudicación (como la celebración y el perfeccionamiento del contrato) hasta la terminación del mismo ${ }^{26}$.

b) Dos reglas especiales de competencia. Existen reglas de competencia, si bien especiales, para: i) los conflictos en los contratos de

${ }^{25}$ Dice el art. 24 incs. $1^{\circ}$ y $2^{\circ}$ LBCA: "El Tribunal será competente para conocer de la acción de impugnación contra actos u omisiones, ilegales o arbitrarios, ocurridos en los procedimientos administrativos de contratación con organismos públicos regidos por esta ley. / La acción de impugnación procederá contra cualquier acto u omisión ilegal o arbitrario que tenga lugar entre la aprobación de las bases de la respectiva licitación y su adjudicación, ambos inclusive."

${ }^{26}$ Tema de lege ferenda que no desarrollo en este trabajo dedicado a la lege data. La doctrina ha criticado este excesivo acotamiento competencial del TCP. Así, LARA y otro, cit. (n. 17), p. 410, lo rebautizan como Tribunal de la "Precontratación" o de la "Formación de la voluntad contractual pública"; Escanilla, cit. (n. 22), p. 112, como "Tribunal para las licitaciones de la Administración", en atención a que, además, en su ámbito subjetivo de conocimiento, no comprende a todos los órganos del Estado, sino sólo a la Administración. Por su parte, VÁSQUEZ y Koch, cit. (n. 22) p. 88-89, se expresa al respecto que "el nombre "Tribunal de Contratación Pública" evoca un concepto que es omnicomprensivo y engloba a toda la contratación administrativa, cuestión que lamentablemente a nuestro juicio, no es así”. Olmos, cit. (n. 21), p. 462 señala en el mismo sentido, con razón, que la competencia del TCP "termina precisamente donde empieza el contrato administrativo". 
obra pública y otros de Vivienda y Urbanización (actos que menciona el art. 3 letra e) LBCA), y ii) los conflictos en la contratación y concesiones de servicio público de las municipalidades (art. 66 LOCM).

\section{Acción de impugnación.}

Para gatillar la competencia del TCP es necesario que un interesado haya ejercido la acción de impugnación que prevé el art. 24 LBCA.

a) Causales específicas de impugnación.- Pese a la acotada competencia del TCP para el conocimiento de asuntos relacionados con la contratación pública, al menos pareciera relativamente amplia la esfera de actos y trámites procedimentales que pueden darse entre la aprobación de las bases de licitación y su adjudicación. Para el caso de la licitación pública, deben ser observados por el órgano de contratación los arts. 20 a 43 y para la licitación privada, los arts. 44 a 48; ambos del Decreto Supremo No250 del Ministerio de Hacienda, de 2004, que aprueba el Reglamento de la $\mathrm{LBCA})^{27}$, sin perjuicio de las demás disposiciones concordantes del mismo texto reglamentario o de la propia Ley ${ }^{28}$.

b) Estadística.- $\mathrm{Al}$ consultar datos oficiales ${ }^{29}$ es posible observar que el número de actos impugnados corresponde en orden descendente a las siguientes materias: $1^{\circ}$ ) resoluciones de adjudicación; $2^{\circ}$ ) resoluciones que declaran desiertas las licitaciones; $3^{\circ}$ ) evaluación de las ofertas; $4^{\circ}$ ) acto de apertura a la licitación; $5^{\circ}$ ) bases de licitación; $6^{\circ}$ ) resoluciones que declaran inadmisibles las ofertas $y, 7^{\circ}$ ) otros casos no especificados.

\section{Todos los órganos de la administración quedan sujetos al TCP}

Es el art. $1^{\circ}$ inc. $2^{\circ}$ LBCA el que establece que todos los órganos administrativos están regidos por la LBCA (salvo algunas excepciones, como las empresas públicas), los que entonces están sujetos a la competencia del TCP en virtud de la regla general de competencia contenida en el art. 24 LBCA. Se ha dado la situación que ante la interposición de acciones de impugnación, un organismo público ha señalado que la LBCA no le es aplicable en la convocatoria de sus procesos licitatorios, debido a que supuestamente se

27 Modificado por Decreto 1410, del Ministerio de Hacienda, de 2015. Éste último viene a reforzar la transparencia en la contratación como las exigencias en el momento de efectuar la licitación, e introduce nuevos elementos, tales como la creación de la "Unión temporal de proveedores" y reglas adicionales.

${ }^{28}$ Muñoz Chiu, Natalia, Contratación administrativa, en Revista de Derecho (Consejo de Defensa del Estado), Nº 12 (2004) pp. 9-11, ofrece una enumeración de varias posibles causales de impugnación.

${ }^{29}$ www.tribunaldecontratacionpublica.cl [consulta 6 de agosto de 2015] 
regiría por normas especiales. La jurisprudencia ha considerado que en lo que a órganos de la Administración se refiere, el TCP tiene amplia competencia para conocer de todos los actos u omisiones que se den en los procedimientos licitatorios, salvo los que se encuentren expresamente excluidos por la Ley, aunque existan normas especiales que regulen ciertas materias de las arbitrariedades e ilegalidades que puedan acaecer dentro del marco competencial del $\mathrm{TCP}^{30}$.

\section{Materias que quedan fuera de la competencia del TCP}

Existen algunas materias propias de la contratación administrativa o de sus fases que han sido excluidas de la competencia del TCP dados los términos del art. 24 LBCA.

a) Celebración y perfeccionamiento del contrato.- El marco competencial establecido por el art. 24 inc. $2^{\circ}$ LBCA es estricto, no admitiéndose el conocimiento de reclamos surgidos en el momento de la adjudicación del contrato, cual es la celebración y perfeccionamiento de éste. El TCP se ha visto en la obligación de declararse incompetente, para conocer y juzgar actos $\mathrm{u}$ omisiones que se lleven a cabo en momentos distintos o posteriores a la adjudicación de la propuesta ${ }^{31}$.

b) Ejecución y terminación del contrato.- Quedan fuera de la competencia del TCP los conflictos suscitados en la ejecución de los contratos sujetos a la LBCA, y otras situaciones que se den independientes del proceso de licitación propiamente tal. Ello no presenta una explicación tan evidente $^{32}$. Contratar con un ente que se comporta a la vez como autoridad es complejo y difícil. Al relegarse la competencia de los actos posteriores a la adjudicación a tribunales sin conocimiento especializado en la materia, se

${ }^{30}$ Véase caso Bosselin Briones Irureta y Hernández Abogados Ltda. con Seremi Metropolitana de Bienes Nacionales (2008).

${ }^{31}$ Como ejemplo de lo anterior podemos mencionar las siguientes sentencias del TCP: i) Centro Médico de Diálisis Diaseal S.A. con Servicio de Salud Metropolitano Suroriente (2006); ii) Correa 3 Arquitectos Limitada con I. Municipalidad de Recoleta (2007); iii) Bosselin Briones Irureta y Hernández Abogados Ltda. con Seremi Metropolitana de Bienes Nacionales (2007); iv) Constructora L y D S.A. con I. Municipalidad de Coyhaique (2011).

${ }^{32}$ En este sentido la doctrina consigna con razón que "[l]a interpretación de un contrato administrativo es un proceso que debe tener en consideración variables y aspectos esenciales (...) donde cohabitan estipulaciones propiamente convencionales con disposiciones potestativas de la Administración", como señala Moraga KLENNER, Claudio, La actividad formal de la Administración del Estado, en PANTOJA BAUZÁ, Rolando (coordinador), Tratado de Derecho Administrativo (Santiago, Abeledo Perrot, 2010), p. 451. 
corre el peligro de una probable aplicación sin tamiz del derecho privado ${ }^{33}$. A mayor abundamiento, se advierte la carga de trabajo que supone para los demandantes tener que dividir el conocimiento de la contienda entre dos instancias, una especializada -ante el TCP-la deseable-, y la otra, general, con un conocimiento limitado de la materia específica ${ }^{34}$.

c) Conflictos en un trato directo.- Quizás interpretando de modo implícito el art. 24 inc. $2^{\circ}$ LBCA se ha entendido que el TCP sólo tiene competencia para las licitaciones; de ahí que el trato directo no podría ser objeto de conocimiento por parte del Tribunal, dado que esta forma contractual tan simplificada no contiene la fase de licitación en su procedimiento, el que sólo está contemplado para las licitaciones públicas y privadas. El TCP lo ha confirmado, señalando que: "[Si] los actos(...) cuya supuesta ilegalidad y/o arbitrariedad se reprocha, por parte de la actora, se han materializado en un procedimiento administrativo de contratación directa, respecto del cual (...) este Tribunal carece de competencia para avocarse su conocimiento y juzgamiento" 35 . Cabría una regla expresa para extender la competencia del TCP a ese caso, pues se enfrenta con el texto del art. 24 LBCA, que pareciera excluir el trato directo.

d) Conflictos en convenios marco.- Los actos ejecutados en base a un convenio marco, por regla general, se encuentran excluidos de los procedimientos de licitación contemplados en el marco de los artículos 7 y 8 LBCA ${ }^{36}$; ello sin perjuicio de que en algún caso el TCP ha afirmado que concurriendo ciertas condiciones y características del proceso de compra podría entrar a conocer de conflictos suscitados en tales procedimientos ${ }^{37}$. Pero en general el TCP en general ha mostrado reticencia al conocimiento de estos conflictos.

e) Acciones resarcitorias (indemnizaciones).- Otro aspecto que está fuera del campo competencial del TCP, es el conflicto indemnizatorio por efecto de una adjudicación realizada en contravención a la normativa o a los elementos que rigen el proceso licitatorio. En efecto, según el tenor literal de la ley, el TCP únicamente está facultado para pronunciarse "sobre la legalidad o arbitrariedad del acto u omisión impugnado" pudiendo ordenar en su caso "las medidas que sean necesarias para restablecer el imperio del derecho" (art. 26 LBCA). Pero esta acción resarcitoria no pareciera ser una "medida necesaria para restablecer el

${ }^{33}$ Lara y otro, cit. (n. 21), p. 423.

${ }^{34}$ Escanilla, cit. (n. 22), p. 136.

${ }^{35}$ Véase: Grupo Bios con Servicio de Salud Metropolitano Sur Oriente (2009).

${ }^{36}$ En ese sentido se ha pronunciado el mismo TCP en Ingeniería y Construcción Ricardo Rodríguez y Cía. Ltda. con Dirección de Compras y Contratación Pública (2011).

37 Ver en ese sentido: Dimacofi S.A. con Ministerio de Obras Públicas (2011). 
imperio del derecho". La jurisprudencia no ha reconocido que el TCP pueda ostentar esta competencia de carácter indemnizatorio o de plena jurisdicción: i) en un caso la Corte Suprema ha señalado lo contrario: que el TCP carece de atribuciones de carácter indemnizatorio ${ }^{38}$; ii) en otro caso ha manifestado que junto con no contar con la competencia necesaria para conocer y juzgar procesos de plena jurisdicción administrativa, las sentencias del TCP no tienen mérito ejecutivo y que no prueban por sí mismas perjuicios en los interesados ${ }^{39}$.

f) Penalizaciones y multas contractuales. - Algo que particularmente se ha dado en la práctica es la aplicación de multas y otras medidas en diferentes momentos del procedimiento licitatorio, por ejemplo, la aplicación de multas más la reparación de perjuicios contra una entidad licitadora que con motivo de haber declarado desierta una licitación perjudicó con ello a un licitante ${ }^{40}$; o también pudiera ser la aplicación de multas a licitadores por incurrir en alguna conducta sancionable ${ }^{41}$.

5. Posibles conflictos de competencia entre el TCP y otros órganos

Pueden existir situaciones en que converjan acciones, órganos y procedimientos en que se conozca y juzgue actos dentro de los procedimiento de compra u otro tipo de actos distintos de los descritos en el Capítulo $\mathrm{V}$ de la LBCA; de igual modo, pueden darse situaciones que susciten dudas o se generen controversias respecto del sentido y alcance de la ley al momento de describir el tipo de actos que pueden alegarse mediante la acción de impugnación. Si bien el sentido de la ley parece claro en cuanto a la esfera de competencia del TCP, se pueden dar algunas situaciones que configuran zonas grises en lo referente a los actos u omisiones impugnados ante el Tribunal. Existen algunos pronunciamientos jurisprudenciales relativos a la competencia del TCP y su delimitación con la competencia de otros órganos, que cabe revisar.

a) Contratación administrativa y recurso de protección.Ha sido frecuente la práctica de los particulares de intentar la interposi-

38 Véase: Servitrans Servicios y Comercio S.A. con Ilustre Municipalidad de Rancagua (2014).

39 Véase el caso: Asesorías y Servicios de Seguridad Empresarial Ltda. con Fisco de Chile (2014).

${ }^{40}$ Véase las sentencias: i) Sergio del Rosario Morales con Dirección de Vialidad Región de Atacama (2006); ii) Eurosolutions E.I.R.L. con Servicio Médico Legal (2007); iii) Instituto Nacionales de Seguridad Integral y Desarrollo de Chile con Hospital Clínico San Borja Arriarán (2008).

${ }^{41}$ Véase Lara y otro, cit. (n. 21), p. 426. 
ción de recursos de protección en el caso de ilegalidades en los procesos de compras públicas o de actos que pronuncie la Administración dentro del mismo. En este contexto, la jurisprudencia se ha pronunciado en el sentido de rechazar acciones de protección sobre la materia de contratación administrativa, por resultar de la exclusiva competencia del $\mathrm{TCP}^{42}$.

b) Contratación administrativa y Contraloría General de la República.- A partir de la creación del TCP la Contraloría General de la República no puede intervenir en los casos que estén siendo conocidos por dicho tribunal, el que tiene competencia exclusiva y excluyente para resolver conflictos en los procedimientos de compras públicas (si bien con las limitaciones que establece la LBCA ${ }^{43}$. Variados han sido los casos en que la Contraloría General de la República se ha pronunciado acerca de su incompetencia para conocer acerca de conflictos que se generen entre la Administración y el administrado en los procesos licitatorios, reafirmando que tal competencia corresponde al $\mathrm{TCP}^{44}$.

c) Responsabilidad de los funcionarios de la administración.- Tanto la Contraloría General de la República como el TCP se han pronunciado en el sentido que aquella es plenamente competente para conocer sobre la responsabilidad funcionaria de los funcionarios de la Administración en los actos que ejecuten dentro del proceso de contratación pública, no entrometiéndose por aquello en la competencia del TCP, cuyo fin es pronunciarse sobre la arbitrariedad y legalidad de los actos y no sobre la responsabilidad funcionaria $a^{45}$.

d) Contratación administrativa y Tribunal de Defensa de la Libre Competencia.- La jurisprudencia se ha pronunciado respecto a acciones y reclamos interpuestos ante el Tribunal de Defensa de la Libre Competencia, señalando que la ley es clara al determinar la esfera (2010)

${ }^{42}$ Ver: Constructora Wormer S.A. con Dirección Regional de Arquitectura MOP

$43 \mathrm{Y}$ en aplicación a la prohibición contenida en la propia regulación del órgano contralor: art. $6^{\circ}$ inc. $3^{\circ}$ ley $\mathrm{N}^{\circ} 10.336$, de 1952, de Organización y Atribuciones de la Contraloría General de la República.

${ }^{44}$ Un dictamen declaró: "Este Ente Fiscalizador debe abstenerse de emitir el pronunciamiento solicitado, por cuanto en virtud de lo dispuesto en el artículo $6^{\circ}$, inciso tercero, de la ley $N^{\circ} 10.336$-de Organización y Atribuciones de esta Contraloría General-, no le corresponde informar ni intervenir en asuntos sometidos al conocimiento de los Tribunales de Justicia, lo que ocurre en la situación planteada en la especie, puesto que esta se vincula directamente con la acción interpuesta ante el aludido tribunal [TCP], en causa rol $N^{\circ} 7$ 2013, la que se encuentra actualmente en tramitación”. Dictamen No 13763, de 2013; en el mismo sentido, Dictámenes $\mathrm{No}_{\text {s. }} 17222$ de 2008 y 57624 de 2013.

${ }^{45}$ En ese sentido ver dictámenes $\mathrm{N}^{\circ}$ s. 23616 de 2008, 3293 de 2011, 13131, de 2013; y caso EMG S.A. con Dirección General de Obras Públicas (2006). 
de la competencia del TCP, y que por tanto en procesos licitatorios no le correspondería pronunciarse $^{46}$.

\section{Procedimiento ante el Tribunal de Contratación PÚBLICA: DESCRIPCIÓN Y PROBLEMAS}

\section{Descripción del procedimiento}

Regulan el procedimiento los arts. 24, 25 y 26 LBCA. Además, el art. 27 LBCA contiene una remisión normativa (reenvío) al Libro I del CPC y a las normas del juicio ordinario civil de mayor cuantía en cuanto "resulten conformes a la naturaleza breve y sumaria de este procedimiento"; de ahí la aplicación supletoria de diversas normas procedimentales del CPC. Cabe destacar las fases o aspectos más relevantes del procedimiento de impugnación ante el TCP.

a) Legitimación activa y plazo de presentación de la demanda.- Conforme al art. 24 inc. $3^{\circ}$ LBCA, ostenta legitimación activa para presentar la acción de impugnación toda persona natural o jurídica que tenga un interés comprometido -puntualiza la ley que éste sea actual- en el procedimiento administrativo de contratación. Para la presentación de la demanda, se establece un plazo fatal de diez días hábiles, computados desde que el interesado tuviese conocimiento del acto u omisión que considere impugnable o desde la publicación de aquél. La demanda, deducida en el plazo fatal señalado, deberá presentarse directamente ante el TCP, sin perjuicio de su presentación por medio de las Intendencias Regionales o Gobernaciones Provinciales, caso que el domicilio del interesado se encuentre ubicado fuera de la ciudad asiento del Tribunal. La Ley indica que este documento deberá contener: i) la mención de los hechos que constituyen el acto u omisión ilegal o arbitraria; ii) identificación de las normas legales o reglamentarias que le sirvan de fundamento, y iii) las peticiones concretas que se sometan a juicio del Tribunal. Si no cumple el demandante con este contenido mínimo, el Tribunal declarará la inadmisión, abriéndose un plazo de cinco días para corregir la impugnación.

b) Informe del organismo público respectivo.- Si se acoge a tramitación la impugnación, el Tribunal notificará al organismo licitatorio respectivo acompañando el texto íntegro de la demanda para que informe sobre la materia objeto de impugnación y las cuestiones conexas que le

46 Puede verse el caso Sonda S.A. con Servicio de Registro Civil e Identificación (2014) en que la Corte Suprema señala de manera lata los argumentos y considerandos para desestimar este tipo de acciones al conocimiento del TDLC. 
plantee el Tribunal, en el plazo fatal de diez días hábiles contado desde la recepción del oficio.

c) Suspensión facultativa del procedimiento licitatorio.Por resolución fundada, el Tribunal podrá decretar la suspensión del procedimiento administrativo en el que recae la acción de impugnación. Para ello el TCP considera tres factores: i) la apariencia de buen derecho en que funde el demandante su demanda; ii) la gravedad de la ilegalidad o arbitrariedad imputada; y iii) los elementos que miren al interés de la comunidad (por ejemplo, si el contrato ya ha sido adjudicado y ya estuviere en ejecución; o la urgencia en la prestación del servicio licitado $)^{47}$.

d) Recepción a prueba del proceso y adopción de diligencias para mejor resolver.- Con independencia que se haya recibido o no el informe del órgano afectado, transcurrido el plazo fatal de diez días, el Tribunal notificará a las partes la recepción a prueba de la causa si estimase que hubiera alguna controversia en relación a algún hecho sustancial y pertinente ${ }^{48}$. Desde la recepción de dicha notificación, se abrirá el término probatorio común de diez días hábiles para rendir todas las pruebas que se soliciten. A partir de la recepción de la causa a prueba, con el objeto de mejor resolver, facultativamente el Tribunal decretará de oficio cualquiera de las medidas enunciadas en el art. $159 \mathrm{CPC} \mathrm{u}$ otras medidas dirigidas a comprobar los hechos controvertidos; las que deberán ser cumplidas en el plazo de diez días hábiles desde la fecha de la resolución que las decreta, y, en todo caso, éstas deberán ser decretadas y cumplidas con anterioridad al vencimiento del término para dictar sentencia. Con independencia de ello, los incidentes promovidos en el juicio no suspenden el curso de éste y se sustancian en ramo separado.

e) Dictación de sentencia definitiva.- Vencido el periodo probatorio, el Tribunal citará a las partes a oír sentencia, momento a partir del cual no podrán presentarse escritos o pruebas de tipo alguno (art. 25 inc. $5^{\circ}$ LBCA); ii) sentencia que debe dictarse en el plazo de diez días contados desde la fecha de la resolución que cita a las partes a oír sentencia (art. 25 inc. final LBCA). En dicha sentencia definitiva, el Tribunal se pronunciará sobre la legalidad o arbitrariedad del acto u omisión impugnado, además de ordenar, si procede, las medidas que sean necesarias para restablecer el imperio del derecho (art. 26 inc. $1^{\circ}$ LBCA).

f) Recurso de reclamación ante la Corte de Apelaciones de Santiago.- Contra dicha sentencia, cabrá recurso de reclamación ante

${ }^{47}$ Arévalo, cit. (n.11), p. 7.

${ }^{48} \mathrm{La}$ práctica ha demostrado que, con independencia de las previsiones legales, el TCP también puede llamar a conciliación entre las partes. 
la Corte de Apelaciones de Santiago, que será conocido en el sólo efecto devolutivo, a interponer en el plazo de cinco días hábiles desde su notificación. Este tribunal de alzada podrá decretar, fundadamente, orden de no innovar por un plazo de hasta treinta días, renovable; y deberá dictar sentencia a más tardar dentro de los diez días hábiles siguiente a aquel en que la causa se haya visto en cuenta o haya quedado en acuerdo. En contra de esta sentencia, dice la ley que "no procederá recurso alguno" (art. 26 inc. final LBCA); de ahí que sólo es posible recurrir ante la Corte Suprema por la vía extraordinaria del recurso de queja.

\section{Aplicación supletoria del CPC. Problemas a que da lugar}

Cabe revisar dos problemas a que ha dado lugar la aplicación de la técnica de integración normativa (supletoriedad) contenida en el art. 27 LBCA en materia de incidentes y juicio ordinario.

a) Aplicación supletoria de las reglas sobre incidentes.- El Libro I del CPC establece disposiciones comunes a todo procedimiento, principalmente relacionado con la sustanciación del proceso y los incidentes. En este caso específico se presenta una dificultad interpretativa relacionada con los incidentes, ya que la única mención que realiza la LBCA a los incidentes está dirigida a establecer que una vez promovidos no suspenderán el curso del juicio y que se tramitarán en cuaderno separado, dejando el resto de la tramitación sujeta a lo señalado en el Título IX del CPC (art. 25 inc. penúltimo LBCA). Si se revisan las normas del $\mathrm{CPC}$ en general no hay inconvenientes salvo el caso de la duración y del periodo probatorio de los incidentes; este período probatorio tiene un plazo de ocho días, el cual puede ser objeto de una ampliación en caso de que el TCP lo estime necesario; es decir, el plazo es prácticamente similar al probatorio de la causa principal en el proceso de impugnación de compras, que abarca 10 días, e incluso este último no tiene posibilidad de extensión. Entonces, dada la aplicación del CPC los incidentes pueden llegar a ocasionar más dilaciones que las regulares del procedimiento principal, lo que va contra la "naturaleza breve y sumaria" del procedimiento ante el TCP (art. 27 LBCA).

b) Aplicación supletoria de las reglas del juicio ordinario.Este punto es el que puede generar mayores inconvenientes al momento de integrar las normas en caso de vacíos o silencios de la LBCA, ya que el proceso ordinario (de lato conocimiento) es radicalmente opuesto al procedimiento ante el TCP que, según el art. 27 LBCA es de "naturaleza breve y sumaria", y si hacemos una interpretación restrictiva de tal naturaleza "breve y sumaria" la aplicación supletoria de las reglas de los juicios ordinarios resultará muchas veces inadecuada, pues tales normas (creadas 
para procedimientos de lato conocimiento) no dan siempre respuesta a los requerimientos de un procedimiento breve y sumario.

Ambos son temas que el TCP debe aquilatar caso a caso.

\section{El cómputo de los plazos ante el TCP. Concepto procesal} de "dias hábiles"

a) Aplicación supletoria de reglas sobre cómputo de plazos. - En este campo se presentan problemas interpretativos dada la norma supletoria contenida en el art. 27 LBCA que reenvía al CPC; de ahí que en cuanto al cómputo de plazos cabe aplicar la regla del CPC y su concepto de "días hábiles" procesales (según el cual se computa el día sábado) y no el concepto de "días hábiles" del procedimiento administrativo (en que no se computa el día sábado).

b) Profusión de plazos de días hábiles en el procedimiento ante el TCP.- Los arts. 22 a 27 LBCA, al regular el proceso de impugnación (artículos que para estos efectos cabe en capsular, pues se refieren a un proceso judicial y no a un procedimiento administrativos, como es el caso de los restantes artículos de la LBCA) utilizan la expresión "días hábiles" en diversos casos, que es la misma expresión del art. 59 CPC, al que reenvía el art. $27 \mathrm{LBCA}^{49}$.

c) Cómputo de plazos de días hábiles en el proceso ante el TCP.- Cabe pronunciarse sobre la forma de computar los plazos de días

${ }^{49}$ Los plazos más importantes señalados en los arts. 24 a 26 LBCA relativos al proceso jurisdiccional ante el TCP son los siguientes:

${ }^{10}$ plazo de presentación de la demanda, de 10 días hábiles computados desde el conocimiento o publicación del acto que pretenda impugnarse (art. 24 inc. $4^{\mathrm{o}}$ LBCA);

${ }^{2^{\circ}}$ plazo de presentación del informe del organismo público licitante para pronunciarse sobre la impugnación, de 10 días hábiles contados desde la recepción del oficio del Tribunal remitiéndole copia de la demanda a éste (art. 25 inc. $1^{\circ}$ LBCA);

${ }^{\circ}$ ) plazo para rendir la prueba en el procedimiento; aquí se establecen tres plazos diferentes, a saber: i) un plazo central para la práctica de la prueba (10 días hábiles desde que se notifique a todas las partes el recibimiento a prueba, según el art. 25 inc. $4^{\circ}$ LBCA); ii) un plazo paralelo de 2 días hábiles a contar desde el mismo momento, para la presentación de la lista de testigos, en su caso (art. 25 inc. $4^{\circ}$ LBCA); y iii) otro plazo paralelo a la apertura de la práctica probatoria de 10 días hábiles, a contar desde la dictación, mediante resolución, de medidas para mejor resolver, para satisfacer lo mandado en dichas medidas (art. 25 inc. $6^{\circ}$ LBCA) ;

$4^{\circ}$ ) plazo para dictar sentencia definitiva, de 10 días hábiles a contar desde la fecha de la resolución que cita a las partes a oír sentencia (art. 25 inc. $7^{\circ}$ LBCA), y

$5^{\circ}$ plazo para interponer recurso de reclamación ante el TCP para ser conocido por la Corte de Apelaciones de Santiago, de 5 días hábiles a contar desde la notificación de la sentencia (art. 26 inc. 2 LBCA). 
"hábiles" en el procedimiento de impugnación ante el TCP (arts. 24 a 27 LBCA), ¿según días hábiles procesales o días hábiles administrativos?: i) días hábiles procesales, del CPC. Por un lado, según el art. 59 CPC para el cómputo de los días hábiles se consideran los días lunes a sábado, salvo los feriados, entendiéndose por éstos últimos los domingos y festivos; y conforme al art. $66 \mathrm{CPC}$ sólo durante tales feriados se entenderá el plazo suspendido (o en mejor expresión, no se computan); salvo que el tribunal disponga lo contrario. Este cómputo se aplica en los procesos ante los tribunales; ii) días hábiles administrativos, de la LBPA. Por otro lado, según el art. 25 LBPA el cómputo de los plazos es de días "hábiles", y para ello se consideran tales sólo los días lunes a viernes, excluyendo los sábados, domingos y festivos. Este cómputo se aplica a los procedimientos administrativos que sustancian órganos administrativos (ex arts. 1, 2 y 25 LBPA) y no se aplica a los procesos judiciales que sustancian los tribunales.

Entonces, en el caso del procedimiento de impugnación ante el TCP, ¿se aplica supletoriamente la regla del CPC o bien la regla de la LBPA? Según la regla supletoria del art. 27 LBCA debe aplicarse el art. 59 CPC y no procede aplicar el concepto de días hábiles contenido en la LBPA al cómputo de plazos del procedimiento ante el $\mathrm{TCP}^{50}$; ello es consistente, además, con la naturaleza del procedimiento (judicial). Dos sentencias del TCP han sostenido este acertado criterio ${ }^{51}$.

d) Problema práctico: el TCP no funciona los días sábado.- Con todo, persiste un problema práctico para la aplicación de este correcto criterio legal: el hecho concreto de que en la actualidad el TCP no funciona los días sábado, lo que implica una falta de cumplimiento estricto al mandato legal; y no resulta ser una excusa la falta de una sede propia. La previsión del Auto Acordado de la Corte Suprema al señalar que "el Tribunal tendrá el mismo horario semanal y diario de funcionamiento que la Dirección" no hace menos irregular esta falta de funcionamiento en los días sábado. A tal punto es efectivo el desapego de la realidad a la regla legal que según informaciones orales proporcionadas en el propio Tribunal la "solución de parche" ha sido aceptar la presentación de las reclamaciones en el domicilio del Secretario, para el caso en que el término recayera en día sábado ${ }^{52}$.

${ }^{50}$ Comparte este criterio: VÁsQueZ y otro, cit. (n. 22), p. 115.

${ }^{51}$ Estas son: i) Ely Lilly de Chile Limitada con Central de Abastecimiento del Sistema Nacional de Servicios de Salud y Sentencia Causa (2006); ii) Bestpharma S.A. con Central de Abastecimiento del Sistema Nacional de Servicios de Salud (2005).

${ }_{52}$ Aspecto éste del ajuste a la realidad del funcionamiento de los órganos del Estado que, para un caso distinto, capta muy bien una sentencia de la Corte de Apelaciones de Concepción de 11 de mayo de 2007, en caso Inmobiliaria San Se- 


\section{Suspensión del procedimiento}

El art. 25 inc. $2^{\circ}$ LBCA le otorga al TCP la atribución de decretar, por resolución fundada, la "suspensión del procedimiento administrativo en el que recae la acción de impugnación”.

a) Efectos prácticos de la suspensión.- La potestad de suspender el proceso de licitación impugnado (ex art. 25 inc. 2 LBCA) se trata de una herramienta clave en grandes procesos, en que se demuestre que la tramitación pueda llegar a ser más extensa que la duración del proceso de licitación impugnado; ya que cabe recordar que la competencia del TCP termina al momento en que se adjudica el contrato, lo cual es independiente de si se encuentra en proceso de litigación. En cuanto a criterios utilizados por el TCP para ejercer esta medida dentro del procedimiento, reafirmando lo indicado, cabe mencionar el periculum in mora [riesgo por el paso del tiempo] y el fumus boni iuris [probabilidad de éxito en el fondo de la cuestión (literal: humo de buen derecho)] del interesado en el ejercicio y mantenimiento de sus derechos ${ }^{53}$. El impacto de la suspensión de una licitación es por sí mismo un incentivo a una mayor diligencia en el actuar de los funcionarios de la Administración, no obstante que en ciertas ocasiones sus efectos pueden ser nefastos para el cumplimiento del objetivo de satisfacer una necesidad pública concreta. Si bien los plazos del proceso son fatales para los interesados, no ocurre lo mismo con los plazos puestos al TCP en razón de sus actuaciones, lo cual es en definitiva respuesta a un asunto práctico, y que por lo mismo puede llevar a ejecutar el proceso en tiempos mayores a lo establecido en la LBCA, y dejar al órgano administrativo sujeto a necesarias extensiones de los servicios contratados, a precios poco convenientes, o recurrir a la no siempre deseable contratación directa ${ }^{54}$.

bastián Ltda. e Inmobiliaria Lomas de San Sebastián Ltda. con Dirección de Aguas (2007). Sobre cómputo de plazos administrativos y judiciales, véase VERGARA BLAN$\mathrm{CO}$, Alejandro, "Cómputo y prórroga de plazos en los procedimientos administrativos especiales. Una correcta aplicación supletoria de la LBPA”, en: Revista de Derecho Administrativo, No2, 2008 (Santiago, LexisNexis) pp. 161-163; y VerGara BlanCo, Alejandro, "Cómputo e interrupción de plazos en el procedimiento administrativo. micrología del principio de certeza jurídica", en: Administración y Derecho (Coordinador E. Soto Kloss, Santiago, LegalPublishing, 2014) pp. 299-312.

53 Véase las siguientes sentencias del TCP: i) Gestión Ecológica de Residuos S.A. con Ilustre Municipalidad de Temuco (2010); ii) Sociedad Genco S.A. con de la Municipalidad de la Pintana (2012); iii) Sociedad E-Sign S.A. con Direccion General de Obras Públicas (2010); iv) Maximiliano Montenegro Peña con I. Municipalidad de Santiago (2011); v) Sagem Scurit S.A. con Servicio de Registro Civil e identificación (2011); vi) 215-2011.

${ }^{54}$ Principalmente basada en la amplia causal del artículo 8 letra c) LBCA: "casos 
b) Suspensión, como institución necesaria en razón de la competencia del TCP.- La institución de la suspensión es estrictamente necesaria por cuanto la competencia del TCP termina al momento de la adjudicación, sin que pueda referirse a fases posteriores a dicho acto $^{55}$. Una evolución jurisprudencial al respecto evitaría la consumación de procedimientos de contratación eventualmente viciosos, de tal manera que mediante los casos sea complementada la regulación de la suspensión del procedimiento, mediante causales desarrolladas jurisprudencialmente, aplicando por ejemplo las bases de la regulación vigente (arts. 9 LOCBGAE y $\left.1^{\circ} \mathrm{LBCA}\right)$. Por ejemplo, es injustificable que ante la falta de suspensión de un procedimiento que no requiera especial atención ni tenga carácter urgente y que se deje continuar procesos licitatorios eventualmente viciosos paralelamente al conocimiento de la causa, pues existiendo una posible ilegalidad en él, y antes de la declaración final de ilegalidad por parte del TCP, el procedimiento pudo haberse suspendido. Cabe evitar la ejecución de todo contrato sospechoso de vicios de nulidad en sus actos previos a la celebración. Mediante la debida ponderación de los intereses en juego, sería esperable el desarrollo de una decidida jurisprudencia en esta línea.

\section{Sobre la no emisión del informe del órgano licitador}

Conforme al art. 25 LBCA, una vez acogida a tramitación la impugnación, el TCP debe oficiar al organismo licitador cuyo obrar haya sido cuestionado para que, en el plazo fatal de 10 días, informe no sólo sobre la materia objeto de impugnación sino también sobre lo demás que inquiera el TCP. En caso que aquél no hubiese remitido el informe dentro del plazo, el TCP continuará con el procedimiento, recibiendo la causa a prueba si estimase la concurrencia de controversias sobre algún hecho sustancial y pertinente, fijando por resolución los puntos controvertidos. En caso de que el órgano licitante no remitiese a tiempo la información precisa, ¿debería al TCP fallar sobre la base únicamente de lo alegado por el licitador reclamante?; ¿debería perjudicar ello a la Administración, al no haber suministrado la información precisa a tiempo, y con consecuencia verse afectado el interés público? Ello no debería ocurrir tan fácilmente, toda vez que el TCP posee la facultad de dictar medidas para mejor resolver, posteriores a la remisión del informe en comento, que pudieran arrojar algo más de luz sobre los hechos enjuiciados.

de emergencia, urgencia o imprevisto, calificados mediante resolución fundada del jefe superior de la entidad contratante".

55 Recurriendo a datos empíricos, es notable el hecho que el 58\% de las causas impugnadas, hasta el 31 de diciembre de 2013, obedecen a la resolución de adjudicación. Fuente: www.tribunaldecompras.cl 


\section{Sobre las medidas que puede adoptar el TCP.}

De la LBCA podemos extraer una doble clasificación de las medidas que puede adoptar el tribunal desde el inicio del procedimiento hasta la dictación de la sentencia; éstas son: las medidas para mejor resolver durante el procedimiento (ex art. 25 inc. $6^{\circ}$ ) y las medidas adoptables con ocasión de la dictación de la sentencia "para restablecer el imperio del derecho" (ex art. 26 inc. $1^{\circ}$ ).

a) Medidas para mejor resolver.- La incidencia que presentan estas medidas se trasladan, como se ve más abajo, al plano práctico, más allá de lo que dispone la literalidad de la Ley, la cual, es de notar, que no sólo las limitan a aquellas previstas en el artículo 159 CPC, sino se extiende a "otras diligencias encaminadas a comprobar los hechos controvertidos". El problema, constatamos, es el poco aprovechamiento que hace el TCP de tales medidas, teniendo una amplia posibilidad de hacer uso de las mismas para ayudar a conformar mejor el contenido de lo que deba resolverse.

b) Medidas para el restablecimiento del imperio del derecho.- El problema que presenta la literalidad de la LBCA en la regulación de estas medidas es doble: primero, no son obligatorias por parte del TCP, sino potestativas; $y$, segundo, no establece la ley un listado de tales medidas ni ejemplo de ellas las cuales quedan así al criterio del órgano jurisdiccional.

El TCP se ha mostrado renuente a dictar medidas tendentes al restablecimiento del imperio del derecho; cabe criticar esta actitud. ${ }^{56}$ No obstante, en un importante fallo sobre la materia la Corte Suprema recalca que la competencia del TCP es amplia y que no sólo se refiere a actos ilegales o arbitrarios, sino que comprende la facultad para adoptar todas las medidas que sean necesarias para corregir las "incorrecciones jurídicas" que se hayan producido durante el proceso de compra, interpretando así el restablecimiento del "imperio del derecho" a que se refiere el art. 26 inc. $1^{\circ}$ $\mathrm{LBCA}^{57}$. La Corte Suprema interpreta las facultades del TCP contenidas

${ }^{56}$ Postula también la adpción de medidas para evitar agravios EsCANILLA, cit. (n. 22), p. 130 y $135-136$.

${ }^{57}$ El Alto Tribunal es muy expresivo al señalar que “ (...) la competencia del tribunal comprende la facultad de adoptar las medidas necesarias para corregir las incorrecciones jurídicas producidas durante el proceso de compra y que dicho órgano jurisdiccional observe en el curso del procedimiento, sin estar limitado exclusivamente a una labor de respuesta al problema planteado, por cuanto se le ha encomendado una labor trascendente en el resguardo de la regularidad legal y racional de los procedimientos objeto de su competencia desarrollados por la Administración, con la obligación expresa de resolver de manera adecuada la impugnación correspondiente. De esta forma debe entenderse el encargo legislativo en orden a adoptar 'las medidas que sean necesarias para restablecer el imperio del derecho' (...). Montenegro con Ilustre Municipalidad de Santiago y Parquimetros y Controles Interparking Limitada (2012). 
en la LBCA de modo amplio, de manera que no sólo sería competente para conocer de actos u omisiones ilegales o arbitrarios que se produzcan en los procesos licitatorios, señalando que además puede aplicar las medidas necesarias para restablecer el imperio del derecho en caso de existir incorrecciones jurídicas en dicho proceso. Habrá que observar la evolución jurisprudencial al respecto.

c) Combinación de suspensión y medidas.- Para que las medidas sean eficaces seguramente tendrían que combinarse con la suspensión previa del procedimiento. En efecto, las medidas adoptadas por el TCP para restablecer el imperio del derecho serán usualmente eficaces en caso que el contrato del particular con la administración no se hubiere celebrado. En un caso en que el TCP declaró que el acto era ilegal y arbitrario, dispuso retrotraer el proceso licitatorio al estado anterior a la evaluación de ofertas; sin embargo (dado que el procedimiento no había sido suspendido), agregó: "Si en la etapa de ejecución de este fallo, se acreditare que (...) [se ha] suscrito el contrato que se deriva de esta licitación y no pudiese, por tal motivo, cumplirse con lo dispuesto (...), se reconoce a la demandante el derecho a entablar en la sede respectiva las acciones jurisdiccionales indemnizatorias que estime pertinentes (...)." ${ }^{58}$ De esta manera se puede apreciar claramente que en la jurisprudencia del TCP el efecto de sus sentencias está condicionado a que no se haya celebrado el contrato licitatorio entre el administrado y la Administración. De ahí que para la eficacia de las medidas, usualmente deberán combinarse con la suspensión del procedimiento.

En otro caso, la Corte de Apelaciones de Santiago, confirma una sentencia del TCP, señalando al efecto ${ }^{59}$ que: "si ya (...) celebraron el respectivo contrato (...) resulta inane disponer que se retrotraiga el estado de cosas al existente antes de la etapa de evaluación de las ofertas, pues pactado dicho contrato éste ha surtido todos sus efectos y no queda a la demandante sino la acción de perjuicios (...). De otro modo, se estaría dejando sin efecto un contrato válidamente celebrado (...) con un tercero ajeno a este pleito (...) lo que evidentemente resulta inaceptable.” ${ }^{60}$

58 Proactiva Servicios Urbanos S.A. con Ilustre Municipalidad de Providencia (2011).

59 Municipalidad de Providencia y otro con Sin registrar (2011).

${ }^{60}$ En el fallo de la Corte de Apelaciones de Santiago un voto disidente defendió la clara posibilidad de anular la licitación, arrastrando también la invalidación del contrato celebrado. Tal voto disidente indica: "Que si el tribunal a quo dispuso que debía retrotraerse la tramitación administrativa del proceso licitatorio (...) no es posible que, a la vez, se sostenga que por el mero hecho de haberse celebrado el contrato (...) tal invalidación no pueda hacerse. Que si se ha celebrado contrato, al derivar éste 


\section{CONCLUSIONES}

10 Para que un proceso de licitación de compras públicas sea exitoso es necesario que exista una regulación adecuada de la materia de fondo, de la contratación administrativa, cuya observancia reviste suma importancia para la transparencia y probidad de la actuación administrativa; pero, tal regulación no tendrá efectos prácticos relevantes si para la ejecución de la misma no se contempla una adecuada instancia de resolución de los conflictos entre la Administración y los administrados de una manera especializada y eficiente.

Los conflictos sobre una parte acotada de la contratación administrativa, como materia especial del Derecho Administrativo y por su importancia económica, ha sido entregada a un órgano jurisdiccional especializado, siendo este hecho un aporte garantista a la tutela de derechos de los administrados ante los eventuales abusos o ilegalidad de los órganos administrativos oferentes.

$2^{\circ} \mathrm{La}$ LBCA crea y regula la organización, competencia y procedimiento ante el TCP cuya naturaleza y misión requiere de una comprobada especialización de sus jueces. Es un tribunal especializado en su finalidad y en su materia; de ahí que en la conformación de ternas para la designación de integrantes y suplentes debe elegirse a candidatos que demuestren experiencia en el tema de la contratación administrativa.

$3^{\circ} \mathrm{El} \mathrm{TCP}$ es un tribunal de derecho, que forma parte del Poder Judicial, sus sentencias producen el efecto de cosa juzgada y pueden ser cumplidas por el propio TCP dada su potestad de imperio.

$4^{\circ} \mathrm{La} \mathrm{LBCA}$ proveyó al TCP de un acotado ámbito competencial para el conocimiento de los casos sobre contratación administrativa limitado a la fase de la licitación, previa a la celebración del contrato administrativo. Quedan fuera de la actual competencia del TCP los actos que se produzcan desde la celebración hasta la terminación del contrato, así como el conocimiento de la indemnización que pudiera corresponderle a un licitador perjudicado por una adjudicación ilegal ya consumada.

$5^{\circ}$ Hay aspectos sobre la organización y el funcionamiento que cabría revisar en aras del aseguramiento de la autonomía de este órgano jurisdiccional y para mejorar su eficiencia en la resolución de casos.

de actos nulos, también debe invalidarse aquel acto jurídico por el efecto extensivo de la nulidad que expresamente ha declarado el Tribunal de Contratación Pública. Y que dicha nulidad afecte a un tercero no puede ser óbice para razonar de la manera como se ha hecho, toda vez que la invalidación del contrato es una consecuencia obvia de la invalidación de la adjudicación (.....” 


\section{BiBLIOGRAFÍA}

Arévalo Adasme, Álvaro, Rol del Juez en el proceso administrativo licitatorio (2014). Discurso en el "Seminario de Contratación Administrativa y Compras Públicas", celebrado el 28 de mayo de 2014 en la Facultad de Derecho de la Pontificia Universidad Católica de Chile. Disponible en http://www.tribunaldecompras.cl [fecha de consulta: 4 agosto 2015].

Bermúdez Soto, Jorge, Derecho Administrativo General (Santiago, Thomson Reuters, 2011).

Costa Cordella, Ezio, Los Tribunales Administrativos especiales en Chile, en Revista de Derecho de la Universidad Austral de Chile, 21(2014) pp. 151-167.

Escanilla Abarza, Eduardo S., El Tribunal de Contratación Pública en Chile. Un análisis crítico propositivo, en Revista de Derecho Público Iberoamericano (2013) pp. 103-149.

Lara Arroyo, José Luis y García-Huidobro Herrera, Luis Eugenio, Aspectos críticos de la solución de controversias en la Contratación Administrativa bajo la Ley No19.886: El caso del Tribunal de Contratación Pública, ahora, en LARA Arroyo, José Luis y Bocksang Hola, Gabriel (coordinadores), Procedimiento Administrativo y Contratación Pública. Estudios a diez años de la entrada en vigencia de las leyes 19.880 y 19.886 (Santiago, LegalPublishing - Thomson Reuters, 2013).

Moraga Klenner, Claudio, Contratación Administrativa (Santiago, Editorial Jurídica de Chile, 2010).

Moraga Klenner, Claudio, La actividad formal de la Administración del Estado, ahora, en Pantoja BauzÁ, Rolando (coordinador), Tratado de Derecho Administrativo (Santiago, Abeledo Perrot, 2010),VII.

Muñoz Chiu, Natalia, Contratación administrativa, en Revista de Derecho (Consejo de Defensa del Estado), Nº 12 (2004) .pp. 9-11.

Olmos Carrasco, Felipe, Aspectos orgánicos y competencia del Tribunal de Contratación Pública, ahora, en Lara Arroyo, José Luis y Bocksang Hola, Gabriel (coordinadores) Procedimiento Administrativo y Contratación Pública. Estudios a diez años de la entrada en vigencia de las leyes 19.880 y 19.886 (Santiago, LegalPublishing - Thomson Reuters, 2013).

VÁsquez SANTANDER, Yuri Antonio - Koch Chacón, Maximiliano Alfredo, Institucionalidad, Procedimiento y Jurisprudencia del Tribunal de Contratación Pública. Análisis Jurisprudencial desde su establecimiento hasta la actualidad (Román Cordero, Cristián, Profesor guía, Memoria para optar al grado de Licenciado en Ciencias Jurídicas y Sociales, Universidad de Chile, 2014).

Vergara Blanco, Alejandro, "Cómputo y prórroga de plazos en los procedimientos administrativos especiales. Una correcta aplicación supletoria de la LBPA”, en: Revista de Derecho Administrativo, No2, 2008 (Santiago, LexisNexis) pp. 161-163.

Vergara Blanco, Alejandro, Esquema del contencioso administrativo: su tendencia hacia un modelo mixto y situación actual del recurso de protección, ahora, en ARANCIBIA M., Jaime - Martínez E., José - Romero S., Alejandro (coordinadores), Litigación Pública, colección Estudios de Derecho Público, Primer Seminario de Litigación Pública (Santiago, Universidad de los Andes, Abeledo Perrot-Thomson Reuters, 2011) pp. 37-63.

Vergara Blanco, Alejandro, "Cómputo e interrupción de plazos en el procedimiento administrativo. micrología del principio de certeza jurídica”, en: Administración 
y Derecho (Coordinador E. Soto Kloss, Santiago, LegalPublishing, 2014) pp. 299-312.

Vergara Blanco, Alejandro, El nuevo paradigma de jurisdicción administrativa pluriforme e hiperespecializada: crónica de una espera, como la de Godot, en Anuario de Derecho Público (2014) pp. 269-292.

Vergara BlanCo, Alejandro, La tendance actuelle du droit chilien pour une jurisdiction administrative hyper-spécialisée, ahora en Mélanges en l'honneur de Pierre Bon (Paris, Éditions Dalloz, 2014), pp. 126-140.

Tribunal de Contratación Pública, Primera Cuenta Pública (2012). Disponible en: http://www.tribunaldecompras.cl [fecha de consulta: 18 marzo 2016].

\section{NORMATIVA CITADA}

Constitución Política de la República de Chile de 1833. Publicación, 25 mayo 1833.

Constitución Política de la República de Chile de 1980. Diario Oficial, 22 septiembre 2005. [CPR].

Ley $\mathrm{N}^{\circ} 1.552$, Código de Procedimiento Civil. Publicación, 30 agosto 1902. [CPC].

Ley $\mathrm{N}^{\circ}$ 7.421, Aprueba el Código Orgánico de Tribunales. Diario Oficial, 9 julio 1943. [COT].

Ley $\mathrm{N}^{\circ} 10.336$, de Organización y Atribuciones de la Contraloría General de la República. Diario Oficial, 29 mayo 1952. [LOACGR].

Ley No 18.575, Orgánica Constitucional de Bases Generales de la Administración del Estado. Diario Oficial, 5 diciembre 1986. [LOCBGAE].

Ley N ${ }^{\circ}$ 18.695, Orgánica Constitucional de Municipalidades. Diario Oficial, 26 julio 2006 [DFL 1, fija el texto refundido, coordinado y sistematizado de la Ley No18.695] [LOCM].

Ley No19.880, establece Bases de los Procedimientos Administrativos que rigen los Actos de los Órganos de la Administración del Estado. Diario Oficial, 29 mayo 2003. [LBPA].

Ley No19.886, Establece Bases sobre Contratos Administrativos de Suministro y Prestación de Servicios. Diario Oficial, 30 julio 2003. [LBCA].

Ley No20.774, Suprime Feriado Judicial, para los tribunales que indica. Diario Oficial, 4 septiembre 2014.

Ley No20.883, Otorga reajuste de remuneraciones a los trabajadores del sector público, concede aguinaldos que señala y concede otros beneficios que indica. Diario Oficial, 2 de diciembre de 2015.

Reglamento de Seguridad Minera, aprobado por Decreto Supremo No132 del Ministerio de Minería. Diario Oficial, 7 febrero 2004.

Reglamento de la Ley No19.886 de Bases Sobre Contratos Administrativos de Suministro y Prestación de Servicios, aprobado por Decreto Supremo $\mathrm{N}^{\circ} 250 \mathrm{del}$ Ministerio de Hacienda, Aprueba. Diario Oficial, 24 septiembre 2004.

Decreto 1410 del Ministerio de Hacienda, modifica el Decreto Supremo no250 de 2004. Diario Oficial, 12 de mayo de 2015.

Auto Acordado de la Corte Suprema de 11 de marzo de 2011 texto refundido, Acta No 16-2011, en: http://autoacordados.pjud.cl/\#parrafo989.

Historia de la Ley No19.886, de Bases sobre Contratos Administrativos de Suministro y Prestación de Servicios, 2003, en www.bcn.cl. 598pp. 
JURISPRUDENCIA CITADA

Jurisprudencia constitucional

Control de constitucionalidad respecto del proyecto de ley de bases sobre contratos administrativos de suministro y prestación de servicios, Tribunal Constitucional, 18 junio 2003 (Rol N³78-03),

Jurisprudencia Judicial

Montenegro Peña, Maximiliano con Municipalidad de Santiago y Parquímetros y Controles Interparking Limitada (2012): Corte Suprema, Rol 1105-2012, 2 agosto 2012. [véase sentencia del TCP: Montenegro con Municipalidad de Santiago].

Servitrans Servicios y Comercio S.A. con Ilustre Municipalidad de Rancagua (2014): Corte Suprema, Rol 10637-2013, 3 abril 2014.

Sonda S.A. con Servicio de Registro Civil e Identificación (2014): Corte Suprema, Rol 13972-2013, 6 agosto 2014.

Asesorías y Servicios de Seguridad Empresarial Ltda. con Fisco de Chile (2014): Corte Suprema, Rol 11.364-2014, 3 septiembre 2014.

Ingenieria y Construcciones P y J Ltda. con Alcalde de la Municipalidad de Vallenar (2005): Corte de Apelaciones de Copiapó, Rol 223-2005, 12 julio 2005.

Inmobiliaria San Sebastián Ltda. e Inmobiliaria Lomas de San Sebastián Ltda. con DGA (2007): Corte de Apelaciones de Concepción, Rol 3637/2005, 11 de mayo de 2007.

Bosselin Briones Irureta y Hernández Abogados Ltda. con Seremi Metropolitana de Bienes Nacionales (2008): Corte de Apelaciones de Santiago, Rol 7311-2007, 9 enero 2008.

Constructora Wormer S.A. con Dirección Regional de Arquitectura MOP (2010): Corte de Apelaciones de Temuco, Rol 11-2010, 12 febrero 2010.

Servicios Socoin Limitada con Municipalidad de Chiguayante (2010): Corte de Apelaciones de Concepción, Rol 482-2010, 25 noviembre 2010.

Municipalidad de Providencia y otro con Sin registrar (2011): Corte de Apelaciones de Santiago, Rol 6587-2011, 2 diciembre 2011.

Fuentes Canales Roxana del Pilar con Municipalidad de San Pedro de la Paz y otros (2013): Corte de Apelaciones de Concepción, Rol 2099-2012, 16 mayo 2013.

Jurisprudencia del Tribunal de Contratación Pública (TCP)

Bestpharma S.A. con Central de Abastecimiento del Sistema Nacional de Servicios de Salud (2005): TCP, Rol 6-2005, 13 diciembre 2005.

Ely Lilly de Chile Limitada con Central de Abastecimiento del Sistema Nacional de Servicios de Salud y Sentencia Causa (2006): TCP, Rol 2-2005, 30 abril 2006.

Centro Médico de Dialisis Diaseal S.A. con Servicio de Salud Metropolitano Suroriente (2006): TCP, Rol 16-2006, 3 octubre 2006.

EMG S.A. con Dirección General de Obras Públicas (2006): TCP, Rol 61-2006, 10 octubre 2006.

Sergio del Rosario Morales con Dirección de Vialidad Región de Atacama (2006): TCP, Rol 85-2006, 9 noviembre 2006.

Correa 3 Arquitectos Limitada con Municipalidad de Recoleta (2007): TCP, Rol 582006, 24 abril 2007. 
Eurosolutions E.I.R.L. con Servicio Médico Legal (2007): TCP, Rol 32-2007, 26 junio 2007.

Bosselin Briones Irureta y Hernández Abogados Ltda. con Seremi metropolitana de Bienes Nacionales (2007): TCP, Rol 41-2007, 25 septiembre 2007.

Instituto Nacional de Seguridad Integral y Desarrollo de Chile con Hospital Clínico San Borja Arriarán (2008): TCP, Rol 6-2008, 11 enero 2008.

Ingeniería y Construcciones del Pacifico Limitada con Dirección de Aeronáutica Civil (2012): TCP, Rol 49-2007, 7 mayo 2009.

Grupo Bios con Servicio de Salud Metropolitano Sur Oriente (2009): TCP, Rol 1152009, 29 octubre 2009.

Sociedad E-Sign S.A. con Dirección General de Obras Públicas (2010): TCP, Rol 782009, 7 enero 2010.

Gestión Ecológica de Residuos S.A. con Municipalidad de Temuco (2010): TCP, Rol 65-2009, 30 marzo 2010.

Constructora L y D S.A. con Municipalidad de Coyhaique (2011): TCP, Rol 69-2010, 17 junio 2011.

Sagem Scurit S.A. con Servicio de Registro Civile identificación (2011): TCP, Rol 852010, 27 junio 2011.

Ingeniería y Construcción Ricardo Rodríguez y Cía. LTDA con Dirección de Compras y Contratación Pública (2011): TCP, Rol 125-2011, 16 agosto 2011.

Montenegro Peña, Maximiliano con Municipalidad de Santiago (2011): TCP, Rol 115-2010, 27 agosto 2011.

Proactiva Servicios Urbanos S.A. con Municipalidad de Providencia (2011): TCP, Rol 99-2011, 1 septiembre 2011.

Dimacofi S.A. con Ministerio de Obras Públicas (2011): TCP, Rol 124-2011, 17 noviembre 2011.

Sociedad Genco S.A. con de la Municipalidad de la Pintana (2012): TCP, Rol 922011, 31 enero 2012.

Helicópteros del Pacífico Ltda. con Corporación Nacional Forestal (CONAF) (2013): TCP, Rol 215-2011, 5 noviembre 2013.

Jurisprudencia Administrativa: Contraloría General de la República (CGR)

Dictamen No 23616 (2008): CGR, 17 marzo 2008.

Dictamen No 17222 (2008): CGR, 15 abril 2008.

Dictamen No 3293 (2011): CGR, 18 enero 2011.

Dictamen $N^{\circ} 13131$ (2013): CGR, 27 febrero 2013.

Dictamen No 13763 (2013): CGR, 28 de febrero de 2013.

Dictamen No 57624 (2013): CGR, 6 de septiembre de 2013. 